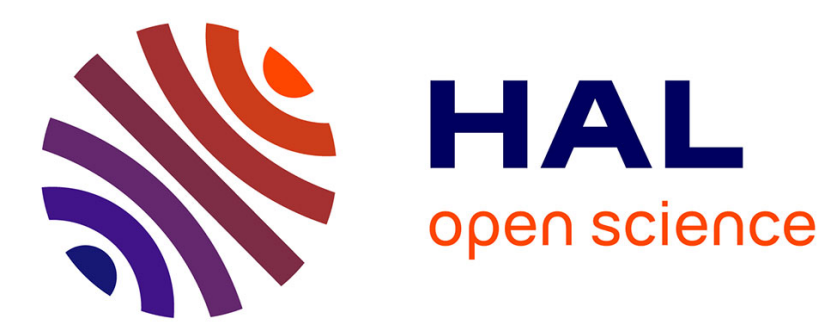

\title{
Discovering surrogate branding via online image development: A case from India
}

Varsha Jain, Philip Kitchen, B.E Ganesh, Akanksha Garg, Manisha Shelat

\section{To cite this version:}

Varsha Jain, Philip Kitchen, B.E Ganesh, Akanksha Garg, Manisha Shelat. Discovering surrogate branding via online image development: A case from India. International Journal of Management Concepts and Philosophy, 2019, 12, 10.1504/IJMCP.2019.10020984 . hal-02280835

\section{HAL Id: hal-02280835 \\ https://hal.science/hal-02280835}

Submitted on 6 Sep 2019

HAL is a multi-disciplinary open access archive for the deposit and dissemination of scientific research documents, whether they are published or not. The documents may come from teaching and research institutions in France or abroad, or from public or private research centers.
L'archive ouverte pluridisciplinaire HAL, est destinée au dépôt et à la diffusion de documents scientifiques de niveau recherche, publiés ou non, émanant des établissements d'enseignement et de recherche français ou étrangers, des laboratoires publics ou privés. 


\title{
Discovering surrogate branding via online image development: a case from India
}

\author{
Varsha Jain* \\ Integrated Marketing Communication, \\ MICA, \\ Shela, Ahmedabad - 380058, India \\ Email: varsha@micamail.in \\ Email: varsha8075@yahoo.co.in \\ *Corresponding author

\section{Philip Kitchen} \\ Salford University, UK \\ and \\ ICN Business School, \\ Nancy, France \\ Email: philipkitchen@hotmail.com

\section{B.E. Ganesh} \\ MICA, \\ Shela, Ahmedabad - 380058, India \\ Email: ganesh_fpm14@micamail.in \\ Email: r.d.maeshtru@gmail.com
}

\author{
Akanksha Garg \\ Amazon Seller Services Pvt. Ltd., \\ Bangalore, India \\ Email: akankshagarg14@micamail.in

\section{Manisha Pathak-Shelat} \\ Communication Area, \\ MICA, \\ Shela, Ahmedabad - 380058, India \\ Email: manisha@micamail.in
}

\begin{abstract}
Internet penetration and usage are accelerating in all countries due to individuals using online platforms to express their views and opinions. These activities are conducted widely in emerging economies such as India. There, internet penetration usage level in 2016 was $34.8 \%$ - primarily undertaken by young adults aged between 18-35 years. While there are multiple studies regarding online image, personal branding, digital sharing and consumption, no
\end{abstract}


extant work has yet explored online activities in terms of projected individual online image though this has been explored offline in terms of self-marketing (Belk, 2013). This projection may be termed 'surrogate branding'. It refers to managing online individual images that help them become digital brands. To assess this further, ethnographic and netnography studies were utilised to understand behavioural patterns and gain insights. The findings revealed four significant dimensions related to surrogate branding of individuals. These are implantation, prenatal, embedded and exultation.

Keywords: surrogate branding; online image; India; conceptual model; qualitative study; young adults; individual images; process of surrogate branding; digital platform usages; personal branding.

Reference to this paper should be made as follows: Jain, V., Kitchen, P., Ganesh, B.E., Garg, A. and Pathak-Shelat, M. (2019) 'Discovering surrogate branding via online image development: a case from India', Int. J. Management Concepts and Philosophy, Vol. 12, No. 3, pp.342-359.

Biographical notes: Varsha Jain is an Associate Professor in Integrated Marketing Communications, Chairperson, Dissertation and co-Chairperson Research. She has authored more than 100 publications. She has won several awards including, Woman Academic Leader Award in Higher Education 2018, Femina Women Leadership Award for Excellence in Education - 2018, DNA Education Leadership Award - 2018, Outstanding Management Researcher Award - 2016, Young Outstanding Management Researcher 2013, and Outstanding Woman Management Researcher - 2012. She was visiting guest at the Emory Business School, Atlanta, USA in April 2018 and April 2017 and at Medill School, Northwestern University, USA in May 2013 and April 2015.

Philip J. Kitchen is a Professor of Marketing at the Salford University Business School, UK and Affiliate Professor at the ICN Business School, Nancy, France and has held a full professorship since 1998. He is an editor of the Journal of Marketing Communications (inaugurated 1996). He has published 20 books and 150 papers in leading journals around the world. He was listed as one of the The Top 50 Gurus who have influenced the Future of Marketing, Marketing Business, December 2003, pp.12-16. He is a Fellow of the CIM, RSA, HEA, IOD; and member of the ALCS and Institute of Marketing Science (USA). He has served as a Visiting Professor of Marketing and/or Communications in many universities/business schools around the world, and advisor to HEI's in terms of strategy and positioning.

B.E. Ganesh is an F.P.M. Scholar in MICA, Ahmedabad, India. He has a Master's in English and has taught at the graduate and post-graduate level for seven years now. His areas of study include philosophy, political theories, theories of persuasion, post modernism, cultural studies and history. He tries to study all the areas of his study with a cross disciplinary focus and interdisciplinary integration. His specialisation in grammar and linguistics has allowed him to develop a practical application protocol for GMAT students that offer a very high degree of accuracy and speed. He has also published extensively in international peer reviewed journals including the Journal of Indian Business Research, Middle East Journal of Management and Organizations and Markets in Emerging Economies. 
Akanksha Garg is the Site Merchandizer at the Amazon Seller Servcies Pvt. Ltd., Bangalore, India. She was an PGDM student at the MICA, India, who specialised in Brand Management. During her course, she has taken part and has been a national finalist in research and analytics-based competitions of Hero Motocorp and IFB Appliances. She interned with Amazon India as part of MICA's Summer Internship Program. She has worked with KPMG and Deloitte Haskins and sells as a consultant. She completed her Bachelor in Business Studies (Marketing) from the Shaheed Sukhdev College of Business Studies, Delhi University.

Manisha Pathak-Shelat is a Professor of Communication and Digital Platforms and Strategies and Chair, Center for Development Management and Communication at the MICA. She has taught and worked as media consultant/trainer and researcher in India, Thailand, and the USA. She has a $\mathrm{PhD}$ in Mass Communication from the University of Wisconsin-Madison, USA and in Education from the Maharaja Sayajirao University of Baroda, India. Her special interests are new media, civic engagement, transcultural citizenship, young people's media cultures, media literacy and gender. She has shared her research on several international platforms and her work has been published in New Media \& Society, Journal of Children and Media, Communication, Media Asia, and as chapters in several books. She has received a number of awards and fellowships including The Soviet Land Nehru Award, Shastri Indo-Canadian Faculty Research Award, The Salzburg Seminar Fellowship and TATA Fellowship for the Study of Contemporary India.

This paper is a revised and expanded version of a paper entitled 'Discovering surrogate branding via online image development: a Case from India' presented at Academy of Marketing Science, AMS Annual Conference 2017, New Orleans, USA, May 2018.

\section{Introduction}

Globally, internet penetration and usage increased exponentially in 2016 to $46 \%$ of the world population (i.e., approximately 3.4 billion people) and showed a $3 \%$ increase from 2015 - concomitant with a world population increase of $1.3 \%$ compared to 2015 . By 2018, the internet users stand at 4.2 billion people across the globe (Statista, 2018). This patterning reflects the individual expression of views, activities, interactions and positioning in the digital space (Internet Live Stats, 2017), total internet users from 2015. For example, India now has the second largest base of internet users. Undoubtedly, online activities are gaining more momentum in emerging countries such as India. As stated in the introduction, in 2016, penetration of internet usage amongst the Indian population reached $34.8 \%$ at 462 million which represents a $7.8 \%$ increase in internet users in the world, signifying that individuals in India use the internet and its accompanying digital platforms extensively for very many daily activities as evidenced in young adults aged between 18-35 (Statista, 2016).

Indeed, $24 \%$ of teenagers go online 'almost constantly'. This is facilitated by the widespread availability of smartphones. Aided by the convenience and constant access provided by mobile devices, especially smartphones, $92 \%$ of teens report go online daily according to a new study from Pew Research Center (Lenhart, 2015). India alone is home 
to 462 million internet users (Statista, 2018). This was specially noticed after India was introduced to Jio Telecom in September 2016. Jio offered VoLTE services at absolutely lower cost, enabling Indians to venture into the world of faster internet. Not only internet, but the entrainment services and bundled applications increased the digital population count in the entire country (PTI, 2018). Thus, young users believe that the majority of their life and rapport building take place online, with the help of technology. This also means that it is imperative for marketers to understand how to be relevant to such users digitally.

These relatively young people strongly hold the view that activities undertaken on digital platforms create, build and augment their online image, which - moreover - is constantly modulated over time (Lenhart, 2015). Online image helps them distinguish themselves through positioning of their online activities. The sought distinction is reflected by these individuals in projecting themselves as brands in their own right. Studies have considered this phenomenon in terms of hermeneutics, online image, personal branding, worldview, digital sharing and consumption (Milovanović et al., 2015; Rui and Stefanone, 2013). However, these studies have not yet integrated and synthesised the key components of this phenomenon. This requires attention for two reasons: first, these young individuals are utilising digital platforms for an entire range of online activities and directing these activities to develop their online image. Second, individuals develop online image in a manner that translates into a component of an individual digital brand.

Given this, the imperative that guides this study is understanding the pattern of activities central to the process of transforming a person into a personified individual brand. Image is central to this. This evolves through surrogate branding which can be seen as a central metaphor that encapsulates the process individuals follow to utilise their online image in developing a self-digital brand. This metaphor was developed from a close correspondence between a corpus of theories and responses provided by individuals studied. Further, it involved the positioning of relevant literature as the deductive base of the study, supplemented by respondent data which acted as an inductive base and outcome of the research. The subsequent sections follow this structure.

\section{Literature review}

\subsection{Surrogate branding: personal branding and online image}

A personal brand develops from the stimulation of meaningful perceptions in audiences about the values and characteristics a person represents - thus creating a digital footprint. This creation involves optimal and focused attention to increase personal visibility and value (Zarkada, 2012). Since the overall focus of this is in the digital space, we consider personal branding in the context of online activities. In order to maximise the personal value and visibility of the consumer in the digital space, it is important to recognise purpose, which refers to the clarity and distinction required at a functional and personal level as to the purpose of a personal branding exercise (Gorbatov et al., 2018). Subsequent to establishing purpose, it is also necessary to develop and consistently follow up a singular vision, which can be summarised as what one may represent at a personal or professional level. Once these two steps are in place, the digital space can be used to reduce the limits of space, appearance and socioeconomic ability (O'Neill et al., 
2017). Further, the steps of purpose and vision become integral to developing the desired image by enhancing the positive qualities and achievements a person possesses and or has achieved or claims relative thereto. Based on these positive qualities and achievements, desired image can be developed based upon consumers having shown performances that can enhance their digital presence. As anticipated, consumers can develop online images. Here, if brands engage with consumers at a deeper and personal level, they may do so by co-creating a digital consumer image (Eigenraam et al., 2018). This would be based on data that the database has garnered about consumer preferences, activities and tastes. After developing a clear profile, online brand information system can utilise the digital space to create hyper-personalised messages and content that resonates with others in terms of their values and preferences. Thus, this is one foundation of surrogate branding.

\subsection{Online image of the individual: digital space}

Online image permits individuals to gain peer approval at an unprecedented pace, volume and scale, similar to celebrity like status (Yue, 2016). Research has found that individuals in an online cohesive group co-generate and reinforce each other's image (Kwon et al., 2017). The image of the individual also gets affected by their professional advantage (Mishra and Agarwal, 2018). Additionally, the leadership styles of the individual also play an important role in reflecting their success (Divya and Suganthi, 2017) which affects their online image. Specifically, this co-generation and reinforcement take the form of consolation and appreciation. Another dimension of these elements is the common interest shared by individuals and groups in the online space (Putnam, 2000). Bonding based on common interest can be experienced and understood through the lens of 'networked individualism'. This network and the associated element of common interests can be elevated by integrating acquired knowledge and shared information online. Such integration serves two purposes. The first is to solidify the objectivity and authenticity of information seekers. Second, it can be used to solidify the reliability and trust of information providers. These complementary information formats are integral to online individual image, which is also influenced by the preferences, wishes, triggers and possible influences of specific individuals and groups (Kozinets, 2002). The reason is that these individuals have limited cognitive potential, which implies selective exposure and attention. This exposure and perception influence the individual's online image. Thus, the two circles help the individual gain a degree of control over specific stimuli - exercised in terms of their online image. Thus, individuals select what are to them the most optimal information sources, social circles and means of projection that are perceived to best consolidate their online image. This image is affected by the perceived usefulness, perceived ease of use, individual attitude and social influence (Verma and Sinha, 2017). This image is further affected by innovation, especially in the context of technology embedded in the world view (Beltramini, 2018) of the individual. Based on this predilection of consumers, further engagement with brands can be anticipated and the technology would help in making memorable experiences of the consumers (Kharat et al., 2018). This could be achieved by establishing the interests and knowledge of consumers and digital platforms consumers use and the platforms of the company could be segued to achieve this. Here, brand communications can showcase the expertise of consumers, which serves a dual purpose. 
The first purpose is that consumer authenticity and stature are maximised because an established brand has featured the consumer in their communication. The second purpose is that brand communication is treated as being more authentic, and simultaneously more consumer centric. Further, the social circles of the consumers and prospective consumers would be more open and receptive to communication centred upon them and peers whom they know rather than on communication merely centred upon the brand. This, therefore, becomes the second step in the process of surrogate branding.

\subsection{Essentials of online image}

The concurrence of the individual and their online presentation of themselves require a symbiotic relation which is active, nonlinear and complex (Maslowska et al., 2016). Further, these characteristics of the relationship can be used to develop emotional, co-creative and meaningful responses for the individual (Gambetti et al., 2012). In order to solidify these responses, there is a need for synchronisation which can carry out at the functional level. This level is necessary as the individual seeks out and positions information with the purpose of enhancing one's well-being. The most salient advantages of this process are: emotional response, co-creative experiences (Gambetti et al., 2012) and meaningful resonance - necessary in that the individual positioning the message realises that messages become the means of developing online individual presentation. Thus, online presentation is an integral part of their well-being (Hennig-Thurau, et al., 2010) and synchronisation should be supplemented via procedural flow which refers to the sequential processes undertaken in order to undertake the three means discussed earlier. Further, procedural flow involves brands possessing effective feedback loops on their digital platforms. These loops facilitate brands in delineating potential negative sentiments and reactions of consumers concerning a brand and its communications. Based on these reactions, the most optimal means of reducing possibilities of disconnections can be determined via brand advertisements and other communications (Kitchen, 2017). This dimension is the last and most important step in surrogate branding. This is because surrogate branding involves the assimilation of consumers' perspectives and engagement with the brand. If this feedback loop is established, the brand could ensure that surrogate branding is set well in place. To summarise, there are studies related to personal branding (Zarkada, 2012; Gorbatov et al., 2018), especially in the context of online space where the individuals develop their digital presence and aim for a desired image. They also seek peer approvals (Yue, 2016) and co-create their image with their social circles. These approvals lead to co-creation of online image of the individuals. Thus, online image becomes complicated and nonlinear (Maslowska et al., 2016). The individual would like to elevate their well-being by providing meaningful experiences. Hence, online representation of this image reflects emotions and reactions of the induvial which would help the brands to communicate their messages effectively to this segment. These connections and understandings also decrease the possibilities of disassociation of consumers with a brand. Thus, it is imperative to understand surrogate branding as it focuses on the consumers' insights and the key dimensions that involve them with the brand. Unfortunately, the studies have been carried out in isolation. For example, personal branding (Gorbatov et al., 2018) and online image have been considered. But there was no study that integrated these two dimensions and provided a meaningful association of these dimensions. Therefore, the objective of the current investigation is to 
discover surrogate branding with a context of online image of the individual which would help the consumers, brands and advertisers to work effectively and provide relevant contextual and meaningful information.

\section{Research design}

\subsection{Methodology}

The exploratory research was conducted qualitatively. Exploratory research offered the means for deep contextual engagement and the means to comprehend emergent nuances. The nature of such exploration led to researchers adopting qualitative methods which can achieve the objectives of the study. Milena et al. (2008) suggest that qualitative methods can facilitate a deeper understanding of expectations and perceptions of the consumers. Further, triangulation of methods was followed to study the research objective via consumer insights, patterns, trends and responses. The methods used were ethnography, netnography and in-depth interviews applied over a four-month period. The data from these methods established and answered the objective of the study. In the seminal work of Guba (1981), the data from the qualitative methods found a new aspect. This aspect was answering the question of validity and reliability of data from qualitative methods, which he affirms as credibility (internal validity) and dependability (reliability) for the qualitative methods data. The dependability is checked through the trustworthiness of the data (Speed et al., 2015). This was ensured by the usage of different methods, prolonged engagement, triangulation of methods used and member checks performed on the respondents as suggested by Guba (1981), Lincoln and Guba (1986) and Shenton (2014). Further justification and explanation of the methods are provided below.

\subsection{Study 1: ethnography}

Market oriented ethnography is a relevant technique focusing on the behaviour of individuals who may become consumers. Specific focus is on the behaviour is studied in terms of products or services (Slevitch, 2011). Here, behaviour was studied in terms of its role in the development of two forms of individual online image. These forms are preferred image and acquired image. The transition from the former to the latter is affected via dissemination and projection. Thus, our ethnographic study involved in-person participant observation in terms of the digital participation and extensions of the respondents. Ethnography helped us understand online preferences, dissemination and acquisition of the online image of the individual. Patterns central to these dimensions were decoded to enable the achievement of research objectives (Cayla and Arnould, 2013). This process was carried out for and completed in a period of three weeks. As a part of this, access was requested and granted to respondents' digital artefacts and platforms. Here, specific aspects and characteristics of the respondents that they wanted to display the most via these platforms were obtained (Serazio, 2015). Subsequently, we ensured that the personal values the respondents emphasised through their digital activities were studied and carefully collated. 
The study and collation were affected on the basis of realist representations, confessional representations, and aspirational modes. These modes helped us come closer to achieving methodological fit in terms of understanding the respondents' preferred image, i.e., how they see themselves. These two forms of images were further supplemented by studying and recognising recurring patterns in terms of which groups mattered to what extent in terms of the respondents' online image (Park and John, 2010). Finally, after studying the patterns of respondents' image requirements and development, we were able to consolidate the building blocks of surrogate branding.

\subsection{Study 2: netnography}

'Netnography' is also known as ethnography on the internet (Bartl et al., 2009). This method examines the online communication of individuals and groups. It utilises data made available through online discussions to recognise and comprehend the needs of connected online customers. It is an invaluable method for discovering consumer insights. These insights are retrieved from the imagery, implications, and utilisation trends of online individuals (Kozinets, 2002). Thus, data was collected by interviews, observations and documents over a period of two months. Therefore, to understand the process of surrogate branding, netnography was very effective as it enabled the study of 'real' conversations and discussions across relevant channels over a specific time period. Through netnography, we studied individuals' usage of Facebook, Twitter, Instagram and WhatsApp accounts. In line with the same, we commenced with the process of sourcing which allowed us to scan the online environment for the most relevant and interactionbased references to brands, categories, product usage situations, and markets by the respondents (Mulvey and Kavalam, 2010). This was followed by tracking - which helped us develop the context of the data in terms of constructs and insights that would help develop a comprehensive and rigorous framework. The subsequent stage was marking which allowed consolidation of observations with regards to the data set in question and the research objectives of the study. Following this was the stage of collecting which involved cross verifying the allocation of data into possible codes for consolidation of the framework (Ritchie et al. 2013).

\subsection{Study 3: depth interviews}

In line of this, we undertook in-depth interviews. These interviews engaged respondents in their personal environment and facilitated the process of gaining access to their deeper engagements in terms of individual feelings and emotions (Pawle and Cooper, 2006). Further, interviews provided nuanced level insights of the consumers as they became involved in an interpersonal exchange of their thoughts and ideas with the interviewer (Malhotra and Dash, 2011). In depth interviews were thus designed to commence from supplementary directions. The first direction was deductive in nature and guided by relevant areas necessary to develop surrogate branding. This direction ensured that questions in interviews were guided coherently. The second direction was inductive in nature. Here, the verbiage and structure of questions in the interviews were not altered. Yet, any unique insight derived from the respondents was accommodated in the form of 
probes and cues (Moran et al., 2014). Deeper insights developed from these cues and probes were further integrated into the constructs of the study. As a final part of this process, the emergence of every meaningful point of insight emergence was treated as a possible source of theme development. This phase also involved understanding that data gained and insights developed thereof were both synchronous and diachronous. Thus, synchronous data and insights represent more immediately situated insights that might or might not possess greater salience over a longer period of time. And diachronous data and insights would represent the data that might not be immediately situated but would still potentially be or not be salient over a longer period of time (Giddens and Brady 2007; Alshenqeeti, 2014).

\subsection{Sampling}

A total of 40 respondents in the age group of 18-35 years were selected for this study given their high comfort level with technology and digital platforms. These respondents were chosen for the present study as they had high digital presence and used online media platforms extensively to express their ideas and thoughts. These expressions were important as the objective of the study was to understand how these expressions and thoughts led to the online image of the individual which thereby developed their surrogate branding. Additionally, they emphasised their online image, which is the base of the surrogate branding of individuals. Further, they also enjoyed independent incomes or were well supported by family members (Goldman Sachs, 2016). Interviews were conducted in the city of Delhi as it has a high rate of internet penetration and online consumption. With a population of 26 million, it is the political capital of India and overall literacy rates of $91 \%$ for men and $80.9 \%$ for women. Participants belonged to the new consumer classification system (NCCS) of MRUC from the A1 and A2 category due to affordability of smart mobile phones, and internet usage (NCCS). This category is also the most brand conscious segment. Additionally, they also enjoy high disposable incomes. And, finally, they do disseminate their views and aspirations via digital platforms.

\subsection{Member check}

Member check is a procedure through which a part or even an entire research report's finding shared with research subjects and participants questioned with the specific goal of requesting their feedback (Manganello et al., 2016). Member checks have proven especially significant for three reasons in relation to differences between traditional ethnography and netnography. They empowered us to acquire and evoke extra, more in-depth extracts of knowledge, which helped decode consumer implications and influences. They were especially important for leading an inconspicuous, observational netnography (i.e., member checks give the chance to be included in advancement and check errors). Second, they improved the argumentative moral concerns, while protecting the estimation of subtle perception (on the grounds that member checks are generally directed after information accumulation and investigation has finished) (Kulavuz-Onal and Vásquez, 2013). Third, and perhaps most vital, this procedure helped set up continuous data exchange between consumer communities and the researchers. Further, netnography was utilised as a base for discussion for continuous, across the board, 
bidirectional correspondence in the midst of associations and groups of respondents. This helped us understand the potential latent in the worldview of the respondents. The methodology followed helped us integrate the theoretical corpus with the respondent data which nonetheless required in depth analysis (Jackson and Mazzei, 2012).

\section{Analysis}

Thematic and content analysis were used for analysing the integration developed from the three methods given the exploratory nature of the study. In line with this, we used the additive approach, which led to a comprehensive understanding of respondents' beliefs and perceptions originating in their life story narratives (Vaismoradi et al., 2013). The process was streamlined using three broad approaches; initial design, in course extension and full frame development (Flick, 2009). Initial design refers to setting the recursive flow of deductive and abductive logic. In course extension refers to the expansion of the data and theoretical frameworks based on the logic. Full frame development is achieved when the data analysed reaches a state of saturation (Singh, 2015). All aided the examination and collation of patterns emergent from the data. Content analysis provided the contextual comprehension of the same. This was possible as we focused on the respondents as the source of the data, the reasons for their response, the intensity of the response and its subsequent effects. Further, content analysis aided in developing an objective and systematic description of respondent insights, which were integrated and categorised based on coherent patterns, developed after identifying, retrieving and comparing salient traits (Braun and Clarke, 2006). The processes followed facilitated development of open coding and led to categories, sub-categories and themes. These divisions facilitated the development of labels that were compared using the second stage of axial coding. The codes developed from the two processes culminated in the theoretical frameworks. This was substantiated by the dictates of theoretical coding (Strauss and Corbin, 1998) used to develop our framework for this study; Process of Surrogate Branding: A Sequential Model.

Figure 1 primarily illustrates three themes: implantation, embedded and exultation. Implantation means the consumer's process of comparing different means of reflecting their life style choices, personal embellishments and domestic aesthetics. The process of implantation is directed by the individual's requirement of power, security and social status. The comparison made by the individuals about the means is based on these three parameters. Hence, they are the sub-themes of implantation as this synchronises consumers' online image at three levels: intra personal, interpersonal and social. The second theme in the framework is embedment. It has two sub-themes: involvement and engagement. The individuals post the alignment of the previous stages displays these two sub themes. Here, embedment refers to the optimised status of the online image they wish to develop by connecting their online image with personalised portrayal, gratification and interpersonal approvals. The final stage subsequent to embedment is exultation. This stage is characterised by the sub-themes of blaring and boasting. This stage represents the dissemination of the online image of the individuals. Here, the individuals wish to project their online image to its full range and potential by decreasing the negative receptions and associating with shared information and projecting them to be proficient. 
Figure 1 Process of surrogate branding

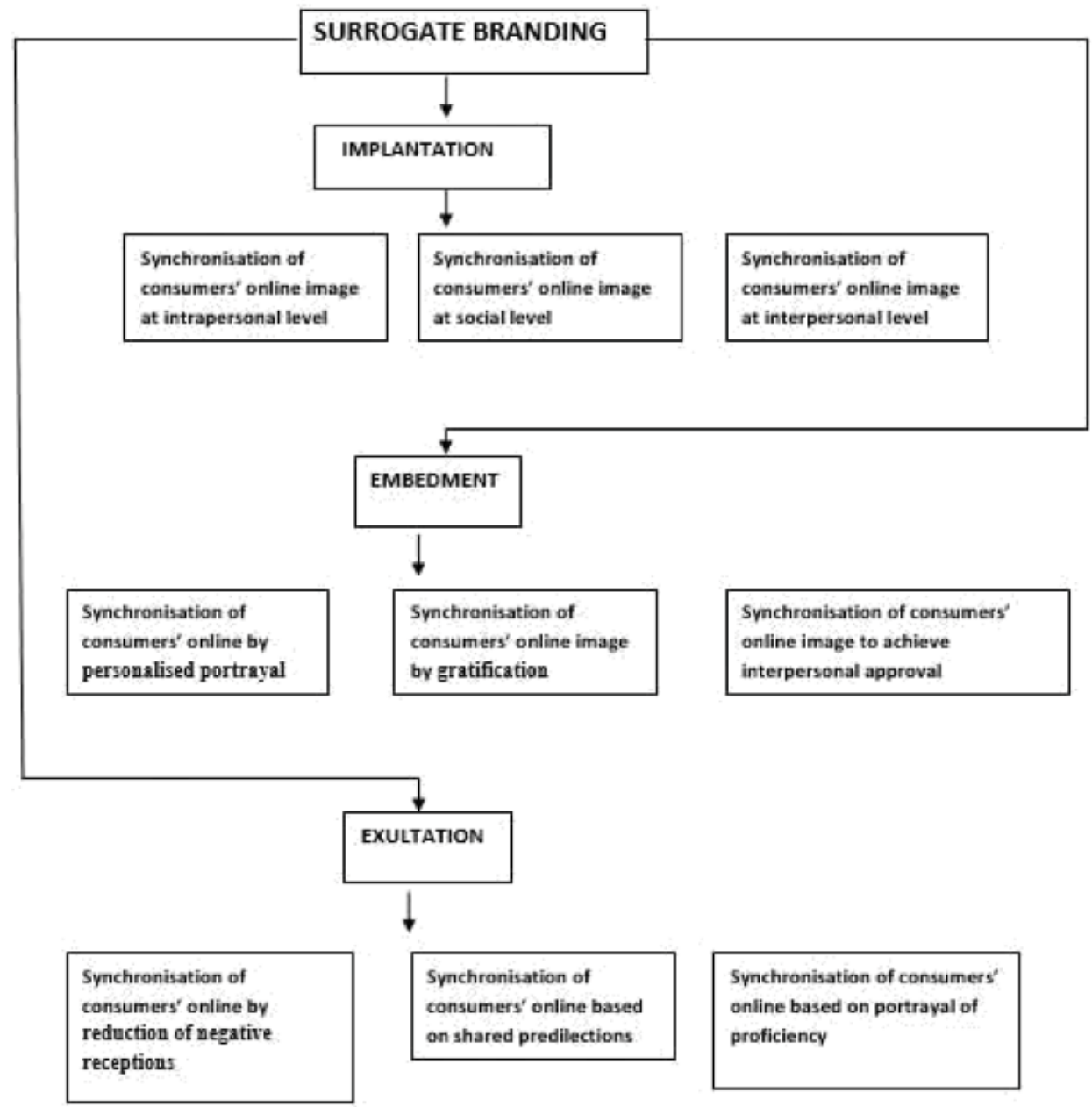

\subsection{Implantation: content congruent with the image}

Implantation is the first key dimension in the process of surrogate branding. It refers to centring on the information the individual wishes to use as a part of his/her online image. This centring takes place on three levels - the intrapersonal, social and interpersonal. These levels are central to understanding the image with which the individual wish to associate most with. Thus, the majority of the respondents stated that the content that the information on the digital platform needs to be congruent with the image they wish to project. This congruence is the first building block of surrogate branding. This building block ensures that the content is in sync with the individual's life style choices, personal embellishment and displayed domestic aesthetics. This insight was re-contextualised by the respondents in terms of their personal choices and specific requirements. Further, the respondents enriched the dimensions of surrogate branding by emphasising on information and knowledge acquisition. This quintessential characteristic was fine 
grained by another respondent. On a related but different tangent, we discovered that even in the lack of proximity, the relevance of the content is a salient factor for individuals. For instance, a respondent observed, "If the person is not close to me but the content he has shared is of my interest then also I will read it with interest" (Male, 25). Thus, we can conclude that the individuals seek and synchronise information at distinct but interrelated levels.

\subsection{Optimised status via the image}

Embedment is the second sequential dimension in the process of surrogate branding. It refers to a well-aligned, functional, conative and personalised integration of the information shared on the digital platform with the optimal means of achieving the preferred online image. This can be achieved by accentuating the power of the individual's image both on an intrapersonal and interpersonal level. This embedment and the optimisation required for the same can be significantly achieved by instituting certain key elements. These elements are personalised portrayal, gratification and interpersonal approval. This was supported by a majority of the respondents. This was further substantiated by another respondent who stated, "I can become the first one who has corrected and authentic information about anything" (Male, 25). These responses are indicative of the self-reflective and functional dimensions of surrogate branding. The next element that emerged from the study was that of subjective self-aspiration. This aspiration defines the responses they provide to cues received from their intended audience. Thus, a respondent said, "I expect them to like or comment on my post" (Male, 27). This was further substantiated by a respondent who said, "If it's a photo, I expect a high number of likes" (Female, 25). The final element that was discovered by the study was that of gratification. Gratification refers to the expected satisfaction and positive state of being they posit as the desired culmination of the activity they pursue. This was substantiated by a majority of the respondents. Specifically, a respondent stated, "A post shared by a person with whom my ideals match will be watched more by me" (Male, 27). Another particular aspect of gratification was the reach of the person on the digital platforms. This was stated by a respondent, "I expect to reach as many people as possible through my social media posts" (Male, 25). Another conclusive element integral to optimisation of status via image was the requirement of consumer to be in veritable limelight. This was stated by a respondent, "Almost all of these brands are on social media and its helps me to be the first one in my peers to know anything latest about the gadgets and other products" (Male, 25). To summarise, optimised status via image is a significant dimension of surrogate branding. The reason for the same is that it encapsulated personalised projections, gratification and interpersonal approval.

\subsection{Disseminated projection of the image}

Exultation is the fourth sequential dimension in the process of surrogate branding. Exultation refers to the external positioning and portrayal of the preferred online image. This positioning and portrayal of the image allows the preferred online image to be appreciated by the intended audience, which includes the reference groups. The degree of appreciation achieved defines the degree of acquisition of the preferred image of the individual. Thus, if the preferred image has received a majority of positive appreciation, 
the individual will have a deeper acquisition of the preferred image. Conversely, if the preferred image has received a majority of negative views, the individual would wish to dissociate themselves from such a negatively evaluated image. This process is affected by certain key elements such as essential display of image, shared predilection and portrayal of proficiency. These elements and processes were discussed by and agreed upon by a majority of the respondents. This response is further substantiated by a respondent who stated, "I want everybody to respect my opinion" (Female, 26). This response was strongly supported in terms of developing an online image. Thus, a respondent stated, "If someone is following me on Facebook or does later on, then I need to build an online image for that. So, at times, I read, so I can share it later and seem genuine" (Female, 22). Additionally, another respondent stated that "I will expect that they will share my post so that other people who do not know can also come to know about me and start following me" (Male, 25). Further, a respondent stated that a shared background and common base of interests influences the decisions of the individual. This view was presented by one of the respondents who said, "For a less expensive product, if a close friend who know me really well says something really good, then I rarely question it and buy it" (Male, 26). This was further extended by another respondent who stated that their decisions were often influenced by "selective specific groups based on the common interest with the group" (Male, 32). In line with the same, it was observed that a part of the acquired online image is derived from expertise. Thus, a respondent shared, "People have started to consider me as a product expert. To have a competitive edge over others, I keep on following this content" (Female, 26). Finally, the respondents explained the role of expertise in the acquired image. This was supported by a respondent who said that due to his expertise, "All my friends and family members come and ask for my advice" (Male, 25). In summary, exultation and disseminated projection of image are key dimensions of surrogate branding. The reason for the same is that it dealt with imperative disclosure related to image, shared inclination and display of expertise.

\section{Discussion}

The objective of the research was to develop a concept and framework related to surrogate branding in the digital context as this is centred on the online image of the individual which led to the unique contributions as this is the novel framework which is developed in the context of online image. This framework also helped in coining a new term 'surrogate branding' in the context of online image development. These unique contributions lead to further micro level implications. First, the framework in Figure 1 may assist companies and organisations to understand the environment, aspirations and processes used by individuals to develop their online image. Second, this image development process culminates in surrogate branding. Comprehending this self-branding would aid companies to customise and personalise information about their products and services inter-alia-brands (Heino et al., 2010). Third, the customisation and personalisation would help increase the receptivity of their target audience to intentional messages. In line with this, our study offers a sequential and systematic process followed by individuals as they develop their online image via surrogate branding.

The conceptualisation of surrogate branding in the context of the digital space and online image of the individuals is a unique contribution emergent from the abductive approach, which was derived from the integration of respondent's responses and the 
theoretical corpus relevant to the study. The corpus we used for this study was related to personal branding, impression management and brand uniqueness. Thus, our study augments understanding the characteristics of the digital environment where individuals are enabled to develop their online image (Barak and Grohol, 2011). However, in earlier literature scholars have just focussed on personal branding (Gorbatov et al., 2018) and explained how the online image is created (Yue, 2016). These studies have mentioned that personal branding is related with the digital footprints and the visibility of the individual in the online space (Theron, 2015). They do not provide a complete process that an individual goes through while they work on their online image and how this image is created by these individuals and can help the brands to provide effective communications (Hyett et al., 2014). The framework of the present study explains all the stages and the levels through which an individual goes through in developing the online image which is a significant contribution to the literate of personal branding and online image.

Our study extended the comprehension of this environment in terms of specific characteristics of cogeneration and reinforcement of user online image. This paper augments these observations and provides a structured process showing that these elements lead to surrogate branding. Earlier studies had identified objectivity and authenticity as key criteria of online image development (Walker, 2010; Zarrella, 2010; Daymon and Holloway, 2011). This paper shows that these criteria can be expanded into four dimensions' integral to surrogate branding. These dimensions were implantation, embedment and exultation. Additionally, earlier studies had stated that the development of the online image was nonlinear. However, our study has found that this development is actually sequential. This characteristic is illustrated in Figure 1. Previous research had identified that the message is imperative to the development of the online image of the individual (Hennig-Thurau et al., 2010). However, our study found that this message is cast into the frames of account, blaring and boasting by individuals.

\section{Implications, limitations and scope for future research}

The first element of surrogate branding was implantation. The dimensions thereof were power, security and social status. This has a significant implication for companies. This implication is that they have to ensure that messages they deliver contain content congruent with online image(s) that individuals wish to portray. This content has to focus on three levels; intrapersonal, interpersonal and social as they are connected closely with the developments of online image. The third implication emerges from effectively implementing the first two implications. Thus, the second implication focuses on embedment. Embedment refers to the customised projection of the desired online image of the individual. This customisation should help the individuals optimally position their online image. Thus, the individuals can gain interpersonal approval. This approval is important as it provides personalised portrayal of individuals' online image which is an instant gratification for these individuals. The final implication is exultation. Companies could mould their messages in terms of the casting the individual uses to disseminate their online image. The messages need to be affirmative as consumers would like to decrease the negative experience in the online space. The consumers also want to share their online experiences which are memorable with their social circles. Thus, brands can 
help them in sharing their thoughts and experiences with the social circles instantly via digital platforms. So, companies would be benefitted, as the individuals would be able to display their expertise and competence. This display would ensure that individuals are better connected to the messages of the company. Further, this connection would lead to higher levels of engagement. The limitation of the present study is that, it is exploratory in nature and thus, future studies can be conducted to quantify the variables and test their relationships. Future studies can supplement this study by using quantitative methods. This could include experiments where scholars can focus on understanding the causal relationship between online image and the dimensions discovered in this study. Future studies can also be conducted to understand how the various levels such as intrapersonal, interpersonal and social work for the consumers while they develop the online image. Scholars can also study the instant effect of gratification that the consumer receives after personalised portrayals of their image with social acceptance in the digital platform. There could be further studies extensively focussing on the consumer reactions towards sharing of information and negative reactions that they receive on the digital platforms. Studies can also aim to generate gender specific objectives. Here, specific genders can be studied exclusively to gain a more nuanced understanding about the online image of these individuals. Scholars can also study separate age groups in terms of the development of the online image. Supplementing these investigations, scholars can also study the cross-cultural perspectives by studying this phenomenon in different national contexts. Lastly, scholars can conduct longitudinal studies to understand the transitions and transformations that individuals undergo at the various phases of online image development.

\section{Acknowledgements}

We gratefully acknowledge the contribution of Ms. Akanksha Garg. Her thesis titled, 'Understanding digital sharing by Gen $\mathrm{Y}$ to different reference groups for product purchase in India' and the data and insights were very helpful while developing this manuscript.

\section{References}

Alshenqeeti, H. (2014) 'Interviewing as a data collection method: a critical review', English Linguistics Research, Vol. 3, No. 1, p.39.

Anon (2017) Number of Internet Users - Internet Live Stats [online] http://www.mruc.net/? $\mathrm{q}=$ new-consumer-classification-system-nccs (accessed 4 February 2016).

Barak, A. and Grohol, J.M. (2011) 'Current and future trends in internet-supported mental health interventions', Journal of Technology in Human Services, Vol. 29, pp.155-196, DOI: 10.1080/15228835.2011.616939.

Bartl, M., Hück, S. and Ruppert, S. (2009) Netnography for Innovation: Creating Insights with User Communities, Research World.

Belk, R.W. (2013) 'Extended self in a digital world', Journal of Consumer Research, Vol. 40, No. 3, pp.477-500.

Beltramini, E. (2018) 'Management innovation and technological culture: a philosophical inquiry', International Journal of Management Concepts and Philosophy, Vol. 11, No. 3, pp.299-314. 
Braun, V. and Clarke, V. (2006) 'Using thematic analysis in psychology', Qualitative Research in Psychology, Vol. 3, No. 2, pp.77-101.

Cayla, J. and Arnould, E. (2013) 'Ethnographic stories for market learning', Journal of Marketing, Vol. 77, No. 2, pp.1-16.

Daymon, C. and Holloway, I. (2011) Qualitative Research Methods in Public Relations and Marketing Communications, Routledge, New York.

Divya, S. and Suganthi, L. (2017) 'Study of authentic-transformational leadership styles in information technology sector - a canonical correlational study', International Journal of Management Concepts and Philosophy, Vol. 10, No. 4, pp.424-444.

Eigenraam, A.W., Eelen, J., Van Lin, A. and Verlegh, P.W. (2018) 'a consumer-based taxonomy of digital customer engagement practices', Journal of Interactive Marketing, Vol. 44, pp.102-121, DOI: 10.1016/j.intmar.2018.07.002.

Flick, U. (2009) An Introduction to Qualitative Research, 4th ed., Sage Publications Ltd, Thousand Oaks, CA.

Gambetti, R.C., Graffigna, G. and Biraghi, S. (2012) 'The grounded theory approach to consumer-brand engagement: the practitioner's standpoint', International Journal of Market Research, Vol. 54, No. 5, pp.659-687.

Giddens, J.F. and Brady, D.P. (2007) 'Rescuing nursing education from content saturation: the case for a concept-based curriculum', Journal of Nursing Education, Vol. 46, No.2, pp.65-69.

Gorbatov, S., Khapova, S. and Lysova, E. (2018) 'personal branding: interdisciplinary systematic review and research agenda', Frontiers in Psychology, Vol. 9, p.2238, DOI: 10.3389/fpsyg.2018.02238.

Guba, E.G. (1981) 'Criteria for assessing the trustworthiness of naturalistic inquiries', ECTJ, Vol. 29, p.75.

Heino, R.D., Ellison, N.B. and Gibbs, J.L. (2010) 'Relation shopping: investigating the market metaphor in online dating', Journal of Social and Personal Relationships, Vol. 27, No. 4, pp.427-447.

Hennig-Thurau, T., Malthouse, E.C., Friege, C., Gensler, S., Lobschat, L., Rangaswamy, A. and Skiera, B. (2010) 'The impact of new media on customer relationships', Journal of Service Research, Vol. 13, No. 3, pp.311-330.

Hyett, N., Kenny, A. and Dickson-Swift, V. (2014) 'Methodology or method? A critical review of qualitative case study reports', International Journal of Qualitative Studies on Health and Well-Being, Vol. 9, No. 23, p.23606.

Jackson, A. and Mazzei, L. (2012) Thinking with Theory in Qualitative Research, New York, NY, Routledge.

Kharat, M., Govind, C., Jha, R.D., Kharat, M.K. and Govind, M. (2018) 'Brand experience: development of the conceptual framework and critical research propositions', International Journal of Management Concepts and Philosophy, Vol. 11, No. 4, pp.340-363.

Kitchen, P.J. (2017) 'Guest editorial', European Journal of Marketing, Vol. 51, No. 3, pp.394-405.

Kozinets, R.V. (2002) 'The field behind the screen: using netnography for marketing research in online communities', Journal of Marketing Research, Vol. 39, No. 1, pp.61-72.

Kulavuz-Onal, D. and Vásquez, C. (2013) 'Reconceptualising fieldwork in a netnography of an online community of English language teachers', Ethnography and Education, Vol. 8, No. 2, pp.224-238.

Kwon, S., Ha, S. and Kowal, C. (2017) 'How online self-customization creates identification? Antecedents and consequences of consumer-customized product identification and the role of product involvement', Computers in Human Behavior, Vol. 75, pp.1-13.

Lenhart, A. (2015) Teens, Social Media \& Technology Overview 2015, Pew Research Center.

Lincoln, Y.S. and Guba, E.G. (1986) 'But is it rigorous? Trustworthiness and authenticity in naturalistic evaluation', New Directions for Program Evaluation, pp.73-84. 
Malhotra, N.K. and Dash, S. (2011) Marketing Research: An applied Orientation, Pearson Publishing, London.

Manganello, J.A., Gerstner, G., Pergolino, K., Graham, Y., and Strogatz, D. (2016) 'Understanding digital technology access and use among New York state residents to enhance dissemination of health information', JMIR Public Health and Surveillance, Vol. 2, No. 1, p.e9.4442.

Maslowska, E., Malthouse, E.C. and Collinger, T. (2016) 'The customer engagement ecosystem', Journal of Marketing Management, Vol. 32, Nos. 5-6, pp.469-501.

Milena, Z.R., Dainora, G. and Alin, S. (2008) 'Qualitative research methods: a comparison between focus-group and in-depth interview', Annals of the University of Oradea, Economic Science Series, Vol. 17, No. 1, pp.1279-1283.

Milovanović, S., Baltazarević, B. and Milovanović, N. (2015) 'Personal branding through leadership', International Review, pp.75-81 [online] https://doi.org/10.5937/intrev1504075M.

Mishra, S. and Agarwal, S. (2018) 'Do business management students have ethical fallout - a study from India?', International Journal of Management Concepts and Philosophy, Vol. 11, No. 4, pp.11-30.

Moran, G., Muzellec, L. and Nolan, E. (2014) 'Consumer moments of truth in the digital context', Journal of Advertising Research, Vol. 54, No. 2, pp.200-204.

Mulvey, M.S. and Kavalam, B.E. (2010) 'Mining deeper meaning in consumer decision maps', Qualitative Market Research: An International Journal, Vol. 13, No. 4, pp.372-388.

O’Neill, B.C., Kriegler, E., Ebi, K.L., Kemp-Benedict, E., Riahi, K., Rothman, D.S., van Ruijven, B.J., van Vuuren, D.P., Birkmann, J. and Kok, K. (2017) 'The roads ahead: narratives for shared socioeconomic pathways describing world futures in the 21st century', Global Environmental Change, Vol. 42, pp.169-180, DOI. 10.1016/j.gloenvcha.2015.01.004.

Park, J.K. and John, D.R. (2010) 'Got to get you into my life: do brand personalities rub off on consumers?', Journal of Consumer Research, Vol. 37, No. 4, pp.655-669.

Pawle, J. and Cooper, P. (2006) 'Measuring emotion - lovemarks, the future beyond brands', Journal of Advertising Research, Vol. 46, No. 1, pp.38-48.

PTI (2018) Reliance Jio Adds 10 Times More Users than Rest of the Players in July - Times of India, The Times of India [online] https://timesofindia.indiatimes.com/business/indiabusiness/reliance-jio-adds-10-times-more-users-than-rest-of-the-players-in-july/articleshow/ 65862152.cms (accessed 4 December 2018).

Putnam, R.A. (2000) Democracy without Foundations, The University of Chicago Press, London.

Ritchie, J., Lewis, J., Nicholls, C.M. and Ormston, R. (2013) Qualitative Research Practice: A Guide for Social Science Students and Researchers, Sage, London.

Rui, J.R. and Stefanone, M.A. (2013) 'Strategic image management online: self-presentation, self-esteem and social network perspective', Information, Communication \& Society, Vol. 16, No. 8, pp.1286-1305.

Goldman Sachs (2016) 'India consumer close up: tapping the spending power of a young, connected urban mass', Equity Research, pp.3-7 [online] https://www.goldmansachs.com/insights/pages/...folder/...india-consumer/report.pdf on 18-012019.

Serazio, M. (2015) 'Branding politics: emotion, authenticity, and the marketing culture of American political communication', Journal of Consumer Culture, Vol. 5, No. 2, pp.1-17.

Shenton, A.K. (2004) 'Strategies for ensuring trustworthiness in qualitative research projects', Education for Information, Vol. 22, pp.63-75, DOI:10.3233/EFI-2004-22201.

Singh, K.D. (2015) 'Creating your own qualitative research approach: selecting, integrating and operationalizing philosophy, methodology and methods', Vision, Vol. 19, No. 2, pp.132-146.

Slevitch, L. (2011) 'Qualitative and quantitative methodologies compared: ontological and epistemological perspectives', Journal of Quality Assurance in Hospitality \& Tourism, Vol. 12, No. 171, pp.73-81. 
Speed, R., Butler, P. and Collins, N. (2015) 'Human branding in political marketing: applying contemporary branding thought to political parties and their leaders', Journal of Political Marketing, Vol. 14, Nos. 1-2, pp.132-135.

Statista (2018) Global digital population 2018, Statistic [online] https://www.statista.com/statistics/ 617136/digital-population-worldwide/ (accessed 4 December 2018).

Statista (2016) Internet Usage in India [online] https://www.statista.com/topics/2157/internetusage-in-india/ (accessed 4 December 2018).

Strauss, A. and Corbin, J. (1998) Basics of Qualitative Research: Procedures and Techniques for Developing Grounded Theory, Sage, Thousand Oaks, CA.

Theron, P.M. (2015) Coding and data analysis during qualitative empirical research in practical theology', In die Skriflig, Vol. 49, No. 3, pp.2-6.

Vaismoradi, M., Turunen, H. and Bondas, T. (2013) 'Content analysis and thematic analysis: implications for conducting a qualitative descriptive study', Nursing \& Health Sciences, Vol. 15, No. 3, pp.398-405.

Verma, P. and Sinha, N. (2017) 'Role of attitude as mediator of the perceived ease of use and behavioural intention relationship', International Journal of Management Concepts and Philosophy, Vol. 10, No. 3, pp.227-245.

Walker, K. (2010) 'A systematic review of the corporate reputation literature: definition, measurement, and theory', Corporate Reputation Review, Vol. 12, No. 4, pp.357-387.

Yue, X.P. (2016) The Re-Construction of Identity and Gender in the Emerging Digital Youth Culture: A Case Study of the Chinese Online Gaming Community, University of British Columbia [online] https://doi.org/10.14288/1.0223807.

Zarkada, A. (2012) Concepts and Constructs for Personal Branding: An Exploratory Literature Review Approach.

Zarrella, D. (2010) The Social Media Marketing Book, O’Reilly Media, Sebastopol, CA. 